\title{
New Biomarkers in the Diagnosis of Kidney Injury in Children with Hereditary Nephritis and Tubulopaties
}

\author{
Hanna Bialkevich, Ina Kazyra, Alexander Sukalo \\ Department of Pediatrics, Belarusian State Medical University, Minsk, Republic of Belarus \\ Email address: \\ belka99@mail.ru (H. Bialkevich)

\section{To cite this article:} \\ Hanna Bialkevich, Ina Kazyra, Alexander Sukalo. New Biomarkers in the Diagnosis of Kidney Injury in Children with Hereditary Nephritis \\ and Tubulopaties. American Journal of Pediatrics. Special Issue: Chronic Kidney Disease in Children. Vol. 6, No. 1, 2020 , pp. $37-41$. \\ doi: 10.11648/j.ajp.20200601.16
}

Received: January 15, 2020; Accepted: February 7, 2020; Published: February 18, 2020

\begin{abstract}
The search of non-invasive methods of diagnosis of kidney disease, new biomarkers of injury and its level is very important at present time. Such markers are KIM-1 (kidney injury molecule - 1), TGF- $\beta 1$ (transforming growth factor - $\beta 1$ ), RBP (retinol-binding protein) and $\beta 2-\mathrm{MG}$ ( $\beta 2$ - microglobulin). $\beta 2-\mathrm{MG}$ and RBP are low molecular weight proteins which are rapidly filtered in the glomerulus and catabolized in the renal tubules after resorption by cells of proximal part. These proteins aren't reabsorbed and appear in the urine in the pathology of the tubules. This fact allows using $\beta 2-\mathrm{MG}$ and RBP for diagnostics of injury of the proximal tubules. KIM-1 isn't detected in normal kidney tissue. However, the expression level of this biomarker increases significantly on the surface of the epithelial cells of the proximal tubules after ischemic or toxic damage of kidneys. For this reasons KIM-1 is an ideal markers of kidney injury and allows differentiating ischemic damage from prerenal azotemia and chronic kidney disease (CKD). TGF- $\beta 1$ indicates endothelial dysfunction and fibroangiogenesis which are the basis of remodeling of the microvascular bed of the kidney in various kinds of glomerulopathies. The results of determination of concentration in serum and urine are presented in this article. The introduction of KIM- 1 , TGF- $\beta 1$, RBP and $\beta 2-\mathrm{MG}$ into clinical practice will expand the possibility of diagnosis of kidney diseases, allow non-invasive monitoring of progression and the effectiveness of nephroprotective therapy.
\end{abstract}

Keywords: Kidney, Injury, Markers, Urine, Serum

\section{Introduction}

Hereditary nephritis and tubulopathies belong to hereditary diseases with kidney injury. The frequency of hereditary nephritis is 1:5000. There is no exact data for tubulopathies but 66 patients are observed in the National Center of Pediatric Nephrology and Renal Replacement Therapy (RRT) in Minsk that is $0.0036 \%$ of healthy children. Despite a low prevalence hereditary syndromes are very important as hereditary nephritis is responsible for $1 \%$ of all cases of CKD in Europe. $2.3 \%$ of all kidney transplantations were performed on patients with hereditary nephritis. According to own data hereditary syndromes make up about $15 \%$ and have the $3^{\text {rd }}$ place in the structure of causes of CKD. At present there are no approved biomarkers that can properly identify kidney injury and its level while routine assessments such as serum creatinine lack sensitivity [1-3]. Several biomarkers such as KIM-1 have been developed to detect acute kidney injury and predict outcomes. Prospective studies investigate, whether the urinary biomarker KIM-1 has prognostic information in CKD as well $[4,5]$. Urine injury biomarkers can be sensitive markers of structural kidney injury and may more accurately predict outcomes [6-9]. So the introduction of new biomarkers into clinical practice will allow timely diagnosing of kidney injury and its level, monitoring the progression and controlling the effectiveness of therapy.

Aim

Determine the concentration of KIM-1, TGF- $\beta 1$, RBP and $\beta 2-\mathrm{MG}$ for the diagnosis of kidney injury in patients with hereditary nephritis and tubulopathies.

\section{Method}

Above mentioned markers were determined in 88 patients who were examined in the National Center of Pediatric Nephrology and RRT for the period from 2017 to 2019. All 
patients were divided into groups: $1^{\text {st }}$ (main) included patients with hereditary nephritis $(\mathrm{n}=19), 2^{\text {nd }}$ (main)-patients with tubulopathies $(\mathrm{n}=16), 3^{\text {rd }}$ (comparison) - patients after acute kidney injury $(n=16), 4^{\text {th }}$ (comparison) - patients with CAKUT $(n=16)$. Healthy children $(n=21)$ were included in the control group $\left(5^{\text {th }}\right)$. All groups are comparable by gender and age. Determination of these markers was carried out by the Enzyme-linked Immunosorbent Assay. Statistical methods of data processing included the determination of the median (Me) and interquartile span (25-75 percentiles). A comparative analysis of the indicators in serum and urine for patients of 2 main groups (U-Mann-Whitney test), between 2 main groups (U-Mann-Whitney), main groups, comparison groups and control (criterion Kruskal-Wallis) was made. $\mathrm{p}<0.05$ (95\% reliability) was taken as the level of statistical significance. The Spearman criterion (r) was used for correlation of the parameters with serum creatinine and glomerular filtration rate (GFR) calculated using the Schwartz formula. Statistical analysis was made using Statistica 10 and Microsoft Excel.

\section{Result}

\subsection{Determination of the Concentration of KIM-1}

There were no significant differences in the concentration

Table 1. Concentration of blood creatinine and GFR in patients with hereditary diseases.

\begin{tabular}{|c|c|c|c|}
\hline \multirow{2}{*}{ Indication } & \multicolumn{2}{|c|}{ Levels of blood creatinine and GFR } & \multirow{2}{*}{$\begin{array}{l}\text { Reliability for both main groups } \\
\text { (U-Mann-Whitney test) }\end{array}$} \\
\hline & $1^{\text {st }}(n=19)$ & $2^{\text {nd }}(n=16)$ & \\
\hline Creatinine, $\mathrm{mmol} / \mathrm{l}, \mathrm{Me}(25-75$ percentiles $)$ & $69(64-95)$ & $77(61-102)$ & $\mathrm{p}=1$ \\
\hline $\mathrm{GFR}, \mathrm{ml} / \mathrm{min} / 1.73 \mathrm{~m}^{2}, \mathrm{Me}(25-75$ percentiles $)$ & $84(64-98)$ & $71(57-84)$ & $\mathrm{p}=1$ \\
\hline
\end{tabular}

There were no significant differences in creatinine and GFR levels in patients in both main groups $(p=1$ for both groups). Four patients from the $1^{\text {st }}$ group and five patients from the $2^{\text {nd }}$ group had a simultaneous increase in creatinine and a decrease in GFR compared to the norm. All nine patients had CKD, one of them received RRT, five - in serum and urine samples in patients of main groups in the Mann-Whitney U-test ( $\mathrm{p}=1$ for both groups). There was no correlation between serum and urine levels of KIM-1 in patients with tubulopathies and hereditary nephritis $(\mathrm{r}=0.06$; $\mathrm{p}=0.819$ and $\mathrm{r}=0.17 ; \mathrm{p}=0.498$ ).

There were no significant differences in the concentration of serum and urinary KIM-1 in patients of the $1^{\text {st }}$ group from patients of the $2^{\text {nd }}$ one $(p=0.514$ and $p=1)$. In the $1^{\text {st }}$ group the concentration of KIM-1 in serum reached the maximum level $(20 \mathrm{ng} / \mathrm{ml})$ in three patients but in the urine this marker remained within the measurement range $(0-20 \mathrm{ng} / \mathrm{ml})$. In the $2^{\text {nd }}$ group serum KIM-1 reached the maximum level in two patients, urinary KIM-1 in one. Three patients out of five who had the highest level of KIM-1 had CKD V stage and received RRT by hemodialysis (one patient), two - kidney transplantation was performed on two patients.

The comparative analysis of KIM-1 concentration between the main groups, comparison and control groups revealed no significant differences $\left(\mathrm{p}_{1-3}=0.861, \mathrm{p}_{1-4}=0.943, \mathrm{p}_{1-5}=0.92, \mathrm{p}_{2 \text { - }}\right.$ ${ }_{3}=1, \mathrm{p}_{2-4}=1, \mathrm{p}_{2-5}=0.893$ for serum KIM- 1 and $\mathrm{p}_{1-3,4,5}=1, \mathrm{p}_{2-}$ $3,4,5=1$ for urinary one).

The most important indicators for the diagnosis of renal failure are serum creatinine and GFR. Levels of them for patients of the both main groups are presented in table 1.
Table 2. Correlation between KIM-1 concentration in blood serum, creatinine and GFR levels in the main groups.

\begin{tabular}{lllll}
\hline \multirow{2}{*}{ Indication } & $\mathbf{1}^{\text {st }}(\mathbf{n}=\mathbf{1 9})$ & & $\mathbf{2}^{\text {nd }}(\mathbf{n}=\mathbf{1 6})$ & $\mathbf{p}$ \\
\cline { 2 - 5 } & Spearman criterion $(\mathbf{r})$ & $\mathbf{p}$ & $\mathbf{S p e a r m a n}$ criterion $(\mathbf{r})$ & $\mathbf{p}$ \\
\hline Creatinine $\mathrm{mmol} / \mathrm{l}$ & 0.19 & 0.426 & 0.34 & 0.194 \\
$\mathrm{GFR}, \mathrm{ml} / \mathrm{min} / 1.73 \mathrm{~m}^{2}$ & -0.19 & 0.448 & -0.32 & 0.234 \\
\hline
\end{tabular}

Table 3. Correlation between KIM-1 concentration in urinary, creatinine and GFR levels in the main groups.

\begin{tabular}{|c|c|c|c|c|}
\hline \multirow{2}{*}{ Indication } & \multicolumn{2}{|l|}{$1^{\text {st }}(n=19)$} & \multicolumn{2}{|l|}{$2^{\text {nd }}(n=16)$} \\
\hline & Spearman criterion (r) & p & Spearman criterion $(r)$ & p \\
\hline Creatinine, $\mathrm{mmol} / \mathrm{l}$ & -0.13 & 0.602 & 0.26 & 0.332 \\
\hline $\mathrm{GFR}, \mathrm{ml} / \mathrm{min} / 1.73 \mathrm{~m}^{2}$ & 0.24 & 0.32 & -0.18 & 0.508 \\
\hline
\end{tabular}

The correlation between creatinine levels, GFR and the concentration of KIM-1 in serum and urine wasn't revealed. However, one patient from the $1^{\text {st }}$ group had a simultaneous increase in serum KIM-1, creatinine and a decrease in GFR. One patient from the $2^{\text {nd }}$ group had a simultaneous increase in urinary KIM-1, creatinine and a decrease in GFR. syndromal therapy, three - kidney transplantation was performed.

A correlation analysis was made to identify the correlation between creatinine levels, GFR, serum and urinary KIM-1 concentrations (tables 2 and 3 ).

\subsection{Determination of the Concentration of RBP}

There were no significant differences in the concentration of RBP in serum and urine samples in patients of main groups in the Mann-Whitney U-test ( $\mathrm{p}=1$ for both groups). The analysis revealed a direct correlation between the level of RBP in serum and urine in patients with tubulopathies 
$(\mathrm{r}=0.76 ; \mathrm{p}=0.001)$, correlation wasn't established for hereditary nephritis $(\mathrm{r}=0.4 ; \mathrm{p}=0.086)$ (figures 1 and 2$)$.

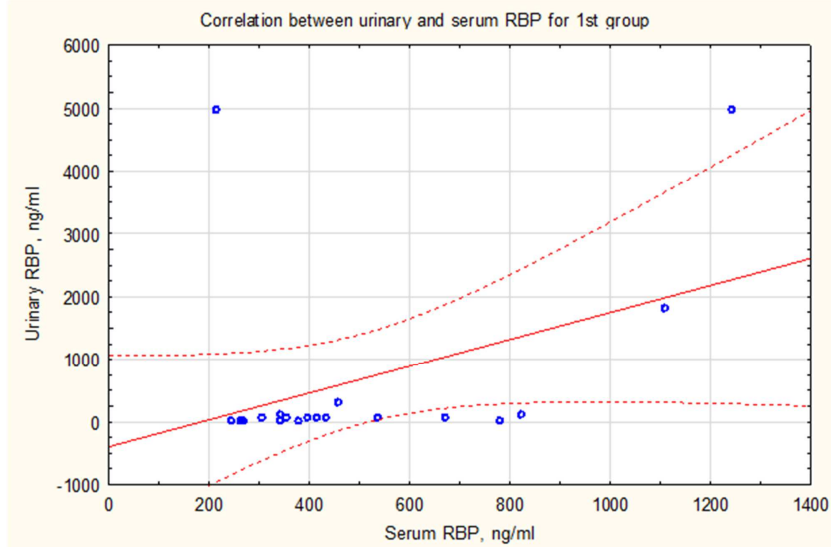

Figure 1. Correlation for RBP in patients with hereditary nephritis.

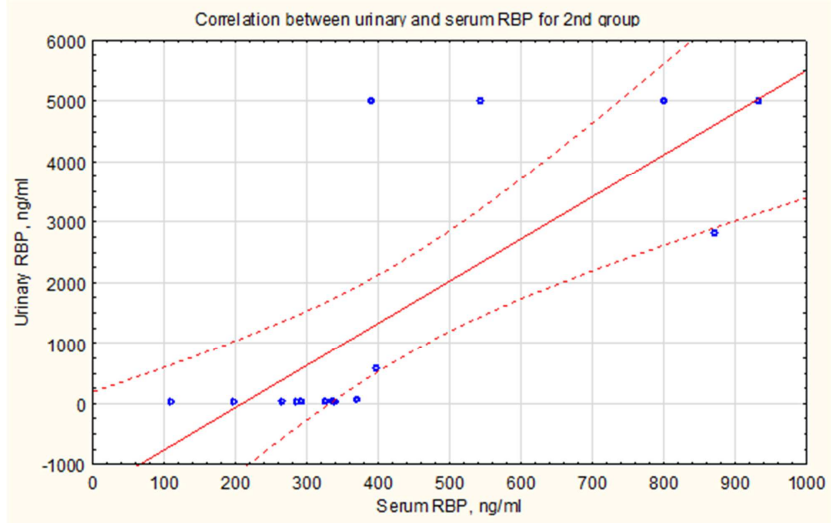

Figure 2. Correlation for RBP in patients with tubulopathies.

The comparison of concentration of serum and urinary RBP in patients of $1^{\text {st }}$ group with $2^{\text {nd }}$ didn't establish significant differences $(p=1)$. RBP in urine reached the maximum level $(5000 \mathrm{ng} / \mathrm{ml})$ in two patients of the $1^{\text {st }}$ group and four patients of the $2^{\text {nd }}$ group with normal in blood. These patients had CKD II-V stages. The comparative analysis of RBP concentration of serum and urinary between the main groups, comparison and control groups revealed no significant differences $\left(\mathrm{p}_{1-3,4,5}=1, \mathrm{p}_{2-3,4,5}=1\right.$ for serum and urinary RBP for main groups).

A correlation analysis was made to identify correlation between creatinine levels, GFR and serum and urinary RBP concentrations. A direct correlation between creatinine $(\mathrm{r}=0.52 ; \mathrm{p}=0.024)$ and serum RBP was established for the $1^{\text {st }}$ group. Correlation between creatinine levels, GFR and RBP in urine wasn't established for both main groups.

A correlation analysis was made to identify the correlation between levels of daily proteinuria and urinary RBP. There was a direct correlation between these indicators for the $2^{\text {nd }}$ group ( $\mathrm{r}=0.82 ; \mathrm{p}=0.0001)$, for the $1^{\text {st }}$ group correlation wasn't established $(\mathrm{r}=0.15 ; \mathrm{p}=0.53)$.

\subsection{Determination of the Concentration of $\beta 2-M G$}

There were significant differences in the concentration of $\beta 2-\mathrm{MG}$ in serum and urine samples in patients of the $1^{\text {st }}$ group $(\mathrm{p}=0.034)$ in the Mann-Whitney U-test, for the $2^{\text {nd }}$ group didn't establish significant differences $(p=0.803)$ (figures 3 and 4).

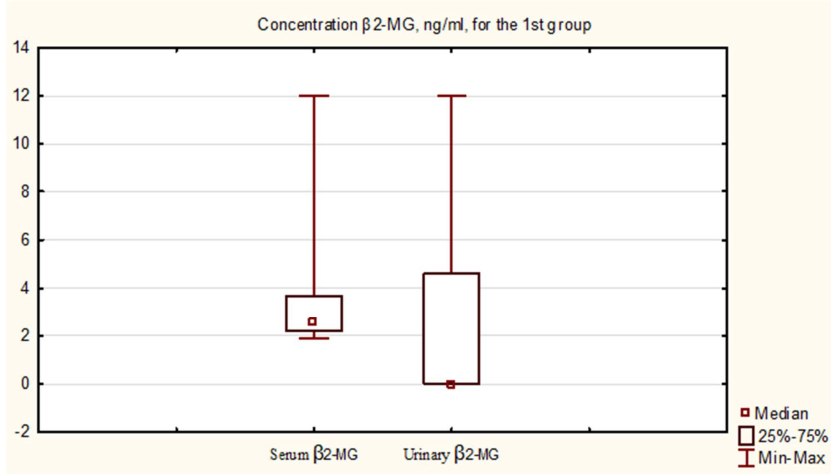

Figure 3. Concentration $\beta 2-M G, n g / m l$, in patients with hereditary nephritis.

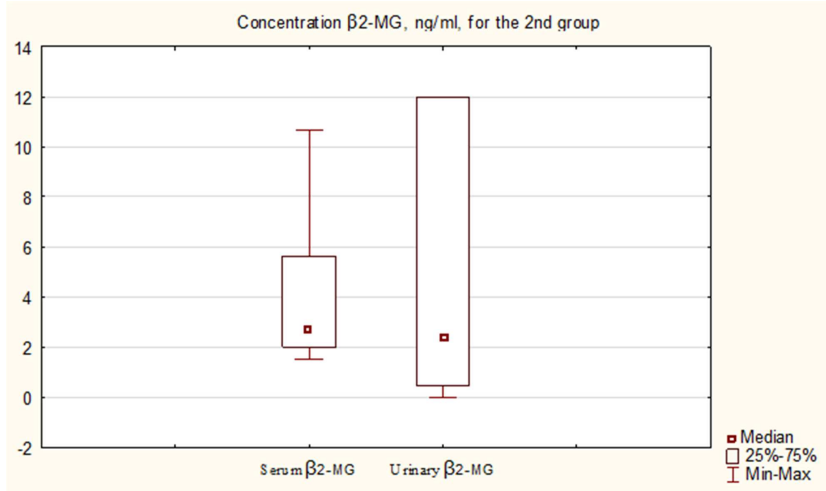

Figure 4. Concentration $\beta 2-M G, n g / m l$, in patients with tubulopathies.

A direct correlation between the level of $\beta 2-\mathrm{MG}$ in serum and urine in patients with tubulopathies $(\mathrm{r}=0.68 ; \mathrm{p}=0.004)$ and hereditary nephritis $(\mathrm{r}=0.62 ; \mathrm{p}=0.005)$ was established.

The comparison of serum and urinary $\beta 2-\mathrm{MG}$ concentrations in the $1^{\text {st }}$ group with patients of the $2^{\text {nd }}$ group showed no significant differences $(\mathrm{p}=1$ and $\mathrm{p}=0.166)$. In the $1^{\text {st }}$ group the concentration of urinary $\beta 2-\mathrm{MG}$ reached a maximum level $(12 \mathrm{ng} / \mathrm{ml})$ in three patients and serum $\beta 2$ $\mathrm{MG}$ in one patient. In the $2^{\text {nd }}$ group urinary $\beta 2-\mathrm{MG}$ reached a maximum level in six patients with normal in blood. Six patients out of nine who had the maximum level of $\beta 2-\mathrm{MG}$ in the urine had CKD II-V stages.

The comparative analysis of $\beta 2-\mathrm{MG}$ concentration of serum and urinary between the main groups, comparison and control groups revealed no significant differences $\left(\mathrm{p}_{1-3,5}=1\right.$, $\mathrm{p}_{1-4}=0.368, \mathrm{p}_{2-3,5}=1, \mathrm{p}_{2-4}=0.368$ for serum and $\mathrm{p}_{1-3,5}=1, \mathrm{p}_{1-}$ ${ }_{4}=0.368, \mathrm{p}_{2-3}=0.688, \mathrm{p}_{2-4}=0.368, \mathrm{p}_{2-5}=1$ for urinary $\left.\beta 2-\mathrm{MG}\right)$.

A direct correlation between creatinine and serum $\beta 2-\mathrm{MG}$ $(\mathrm{r}=0.59 ; \mathrm{p}=0.015)$ was established for the $2^{\text {nd }}$ group There was direct correlation between creatinine and urinary $\beta 2-\mathrm{MG}$ $(\mathrm{r}=0.61 ; \mathrm{p}=0.013)$ and indirect correlation between the level of GFR and $\beta 2-M G$ in the urine $(r=-0.51 ; \mathrm{p}=0.045)$ for the $2^{\text {nd }}$ group. There is no correlation between these indicators for the $1^{\text {st }}$ group.

A correlation analysis was made to identify the correlation 
between levels of daily proteinuria and urinary $\beta 2-\mathrm{MG}$. There was a direct correlation between these indicators for the $2^{\text {nd }}$ group $(\mathrm{r}=0.52 ; \mathrm{p}=0.041)$, for the $1^{\text {st }}$ group correlation was not established $(\mathrm{r}=0.2 ; \mathrm{p}=0.416)$.

\subsection{Determination of the Concentration of TGF- $\beta 1$}

There were significant differences in the concentration of TGF- $\beta 1$ in serum and urine samples in patients of the $1^{\text {st }}$ group $(p<0,001)$ and the $2^{\text {nd }}$ group $(p<0,001)$ in the MannWhitney U-test. There was no correlation between the level of TGF- $\beta 1$ in serum and urine in patients with tubulopathies and hereditary nephritis $(r=0.07, p=0.765$ and $r=-0.07$, $\mathrm{p}=0.755)$.

There were significant differences in the concentration of TGF- $\beta 1$ in serum in patients of the $1^{\text {st }}$ group with patients of the $2^{\text {nd }}$ one $(p=0.003)$, for urinary TGF- $\beta 1$ significant differences didn't establish ( $\mathrm{p}=1)$ (figures 5 and 6).

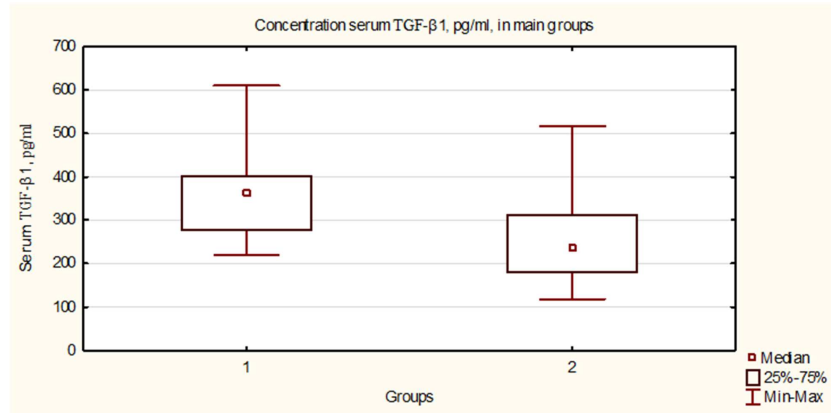

Figure 5. Comparison of concentration serum TGF- $\beta 1$ in patients of main groups.

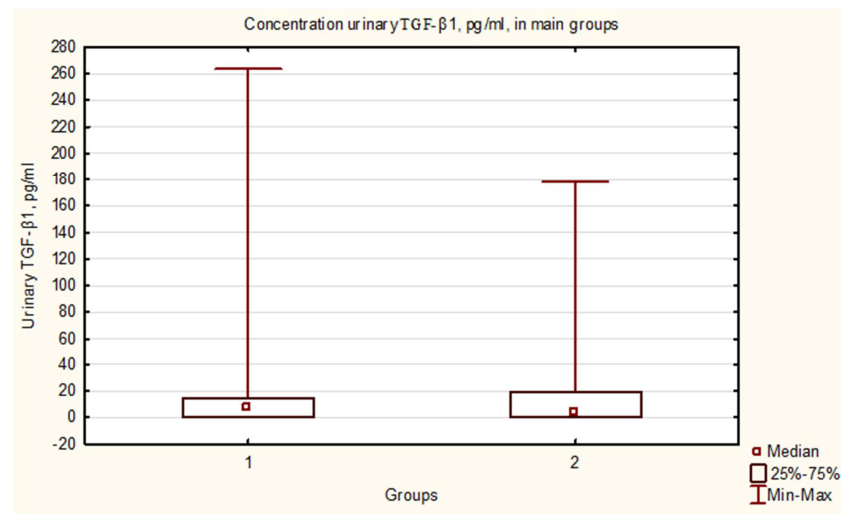

Figure 6. Comparison of concentration urinary TGF- $\beta 1$ in patients of main groups.

In the $1^{\text {st }}$ group concentration of serum TGF- $\beta 1$ reached maximum level $(610 \mathrm{pg} / \mathrm{ml})$ in one patient. This patient had CKD and received RRT by hemodialysis.

The comparative analysis of TGF- $\beta 1$ concentration of serum and urinary between the main groups, comparison and control groups revealed no significant differences $\left(\mathrm{p}_{1-3,4,5}=1, \mathrm{p}_{2-3,4,5}=1\right.$ for serum and $\mathrm{p}_{1-3,4,5}=1, \mathrm{p}_{2-3,4,5}=1$ for urinary TGF- $\left.\beta 1\right)$.

A correlation analysis was made to identify the correlation between creatinine levels, GFR, serum and urinary TGF- $\beta 1$ concentrations. There isn't correlation between these indicators for both groups.

\section{Discussion}

The present study was designed to determine the concentration of KIM-1, TGF- $\beta 1$, RBP and $\beta 2-\mathrm{MG}$ for the diagnosis of kidney injury in patients with hereditary nephritis and tubulopathies.

Data from literature indicate that KIM-1 have been developed to detect acute kidney injury and predict outcomes [3-8]. Most biomarkers of acute kidney injury have been shown to be expressed before rise of serum creatinine and to be more sensitive and specific than urine output. Only a few studies have examined how implementation can change clinical outcomes $[3,4,6]$. Prospective studies investigate, whether the urinary biomarker KIM-1 has prognostic information in CKD as well [5].

In our study concentration of KIM-1 in serum reached the maximum level in five patients, three $p$ out of five with the highest level of KIM-1 had CKD V stage. The comparative analysis of KIM-1 concentration between the main groups, comparison and control groups revealed no significant differences. Like the traditional indicators (creatinine, albuminuria) KIM-1 can be using candidate prognostic biomarkers in CKD.

Tsai YL et al. revealed 5 synergetic predictors including RBP for the CKD progression in patients with hypertension and proteinuria. In comparison with CKD stable group the positive correlation between urinary RBP versus severity of albuminuria were noted among CKD progression group. [9].

Qin Y et al. analyzed patients with diabetic kidney disease had higher levels of all six urinary biomarkers (transferrin, immunoglobulin G, RBP, $\beta$ - galactosidase, N-acetyl-beta glucosaminidase and $\beta 2-\mathrm{MG}$ ). All indicators demonstrated significantly increased risk of diabetic kidney disease. Single RBP yielded the greatest area under the curve (AUC) value of 0.920 compared with the other five markers. The diagnostic values of the different combinations were not superior to the single RBP [10].

In our study were no significant differences in the concentration of RBP in serum and urine samples in patients of main groups. However, RBP in urine reached the maximum level in six patients of main groups with normal in blood. These patients had CKD II-V stages. A direct correlation between creatinine $(r=0.52 ; p=0.024)$ and serum RBP and levels of daily proteinuria and urinary RBP will allow diagnosing of kidney injury and monitoring the progression using RBP as a new biomarker.

Zhang $\mathrm{L}$ et al. recently established cystatin $\mathrm{C}$, urinary micro-albumin and $\beta 2-\mathrm{MG}$ can reflect the renal injury effectively, and the combined measurements shows potent accuracy in diagnosis of the early renal injury in pregnancyinduced hypertension syndrome, thereby providing the scientific evidence for early diagnosis and stipulation of rational therapeutic regimen and improving the pregnancy outcome [11].

In our study were significant differences in the concentration of $\beta 2-\mathrm{MG}$ in serum and urine samples in patients with hereditary nephritis. This fact will allow using 
serum $\beta 2-\mathrm{MG}$ for diagnosis of glomerular diseases. But urinary $\beta 2-\mathrm{MG}$ reached the maximum level in nine patients of main groups. Six patients out of nine who had the maximum level of $\beta 2-\mathrm{MG}$ in the urine had CKD II-V stages. This data will allow using urinary $\beta 2-\mathrm{MG}$ for diagnosis of CKD in patient with tubular diseases.

According to Higgins SP, et al. CKD, in particular, constitutes an increasing medical problem affecting $>15 \%$ of the US population. Regardless of etiology (diabetes, hypertension, ischemia, acute injury, urologic obstruction), persistently elevated TGF- $\beta 1$ levels are causatively linked to the activation of profibrotic signaling networks and disease progression. TGF- $\beta 1$ is the principal driver of renal fibrogenesis, a dynamic pathophysiologic process that involves tubular cell injury/apoptosis, infiltration of inflammatory cells, interstitial fibroblast activation and excess extracellular matrix synthesis/deposition leading to impaired kidney function and, eventually, to chronic and endstage disease [12]. Li $\mathrm{H}$ et al. notes TGF- $\beta$ signaling plays a principal role in renal fibrosis, but the precise mechanisms and the downstream factors are still largely unknown [13].

We established were significant differences in the concentration of TGF- $\beta 1$ in serum and urine samples in patients of main groups. The concentration of TGF- $\beta 1$ in serum was significantly higher in patients with hereditary nephritis compared to patients with tubulopathies. This fact allows using TGF- $\beta 1$ as a marker of development of glomerulosclerosis.

\section{Conclusion}

In conclusion, KIM-1 and RBP are not informative for the diagnosis of tubulopathies and hereditary nephritis in patients with normal kidney functions but these markers can be used for diagnosis of CKD and monitoring of progression. $\beta 2-\mathrm{MG}$ is informative for non-invasive diagnosis of tubular diseases and monitoring of the progression of CKD in patients with tubulopathies and we can use serum $\beta 2-\mathrm{MG}$ as additional markers for diagnosis of glomerular diseases. TGF- $\beta 1$ can be used for prediction of development of glomerulosclerosis.

\section{References}

[1] Nafea OE, Zakaria M, Hassan T, El Gebaly SM, Salah HE. Subclinical nephrotoxicity in patients with beta-thalassemia: role of urinary kidney injury molecule. Drug Chem Toxicol. 2019 Sep 5: 1-10. doi: 10.1080/01480545.2019.1660362.

[2] Falcone S, Wisby L, Nicol T, Blease A, Starbuck B, Parker A, Sanderson J, Brown SDM, Scudamore CL, Pusey CD, Tam FWK, Potter PK. Modification of an aggressive model of Alport Syndrome reveals early differences in disease pathogenesis due to genetic background. Sci Rep. 2019 Dec 31; 9 (1): 20398. doi: 10.1038/s41598-019-56837-6.

[3] Tanase DM, Gosav EM, Radu S, Costea CF, Ciocoiu M,
Carauleanu A, Lacatusu CM, Maranduca MA, Floria M, Rezus C. The Predictive Role of the Biomarker Kidney Molecule-1 (KIM-1) in Acute Kidney Injury (AKI) CisplatinInduced Nephrotoxicity. Int J Mol Sci. 2019 Oct 22; 20 (20). pii: E5238. doi: 10.3390/ijms20205238.

[4] Srisawat N, Kellum JA. The Role of Biomarkers in Acute Kidney Injury. Crit Care Clin. 2020 Jan; 36 (1): 125-140. doi: 10.1016/j.ccc.2019.08.010.

[5] Seibert FS, Sitz M, Passfall J, Haesner M, Laschinski P, Buhl M, Bauer F, Babel N, Pagonas N, Westhoff TH. Prognostic Value of Urinary Calprotectin, NGAL and KIM-1 in Chronic Kidney Disease. Kidney Blood Press Res. 2018; 43 (4): 12551262. doi: $10.1159 / 000492407$.

[6] Yin W, Kumar T, Lai Z, Zeng X, Kanaan HD, Li W, Zhang PL. Kidney injury molecule-1, a sensitive and specific marker for identifying acute proximal tubular injury, can be used to predict renal functional recovery in native renal biopsies. Int Urol Nephrol. 2019 Dec; 51 (12): 2255-2265. doi: 10.1007/s11255-019-02311-1.

[7] Laurentino MR, Parente Filho SLA, Parente LLC, da Silva Júnior GB, Daher EF, Lemes RPG. Non-invasive urinary biomarkers of renal function in sickle cell disease: an overview. Ann Hematol. 2019 Dec; 98 (12): 2653-2660. doi: 10.1007/s00277-019-03813-9.

[8] Koyawala N, Reese PP, Hall IE, Jia Y, Thiessen-Philbrook HR, Mansour SG, Doshi MD, Akalin E, Bromberg JS, Harhay MN, Mohan S, Muthukumar T, Schröppel B, Singh P, Weng FL, Parikh CR. Urine injury biomarkers are not associated with kidney transplant failure. Transplantation. 2019 Sep 13. doi: 10.1097/TP.0000000000002948.

[9] Tsai YL, Liu CW, Huang SF, Yang YY, Lin MW, Huang CC, Li TH, Huang YH, Hou MC, Lin HC. Urinary fatty acid and retinol binding protein- 4 predict CKD progression in severe NAFLD patients with hypertension: 4-year study with clinical and experimental approaches. Medicine (Baltimore). 2020 Jan; 99 (2): e18626. doi: 10.1097/MD.0000000000018626.

[10] Qin Y, Zhang S, Shen X, Zhang S, Wang J, Zuo M, Cui X, Gao Z, Yang J, Zhu H, Chang B. Evaluation of urinary biomarkers for prediction of diabetic kidney disease: a propensity score matching analysis. Ther Adv Endocrinol Metab. 2019 Dec 2; 10: 2042018819891110. doi: $10.1177 / 2042018819891110$.

[11] Zhang L, Sun J, Zhang M, Lin Y, Fang L, Fang X, Mai W, Yin $Z$. The significance of combined detection of CysC, urinary $\mathrm{mAlb}$ and $\beta 2-\mathrm{MG}$ in diagnosis of the early renal injury in pregnancy-induced hypertension syndrome. Saudi J Biol Sci. 2019 Dec; 26 (8): 1982-1985. doi: 10.1016/j.sjbs.2019.07.013.

[12] Higgins SP, Tang Y, Higgins CE, Mian B, Zhang W, Czekay RP, Samarakoon R, Conti DJ, Higgins PJ. TGF- $\beta 1 / \mathrm{p} 53$ signaling in renal fibrogenesis» Cell Signal. 2018 Mar; 43: 110. doi: 10.1016/j.cellsig.2017.11.005.

[13] Li H, Cai H, Deng J, Tu X, Sun Y, Huang Z, Ding Z, Dong L, Chen J, Zang Y, Zhang J. TGF- $\beta$-mediated upregulation of Sox9 in fibroblast promotes renal fibrosis. Biochim Biophys Acta Mol Basis Dis. 2018 Feb; 1864 (2): 520-532. doi: 10.1016/j.bbadis.2017.11.011. 